\title{
Dermoscopic Features as Predictors of BRAF Mutational Status and Sentinel Lymph Node Positivity in Primary Cutaneous Melanoma
}

\author{
Nika Filipović ${ }^{1}$, Mirna Šitum ${ }^{1,2}$, Marija Buljan $^{1,2}$
}

\begin{abstract}
1 Department of Dermatology and Venereology, University Hospital Centre Sestre Milosrdnice, Zagreb, Croatia 2 Department of Dermatovenereology, School of Dental Medicine, University of Zagreb, Croatia
\end{abstract}

Key words: melanoma, $B R A F$, sentinel lymph node, dermoscopy

Citation: Filipović N, Šitum M, Buljan M. Dermoscopic features as predictors of BRAF mutational status and sentinel lymph node positivity in primary cutaneous melanoma. Dermatol Pract Concept. 2021;11(2):e2021040. DOI: https://doi.org/10.5826/dpc.1102a40

Accepted: November 23, 2020; Published: April 12, 2021

Copyright: @2021 Filipović et al. This is an open-access article distributed under the terms of the Creative Commons Attribution License BY-NC-4.0, which permits unrestricted noncommercial use, distribution, and reproduction in any medium, provided the original authors and source are credited.

Funding: None.

Competing interests: The authors have no conflicts of interest to disclose.

Authorship: All authors have contributed significantly to this publication.

Corresponding author: Nika Filipović, MD, Department of Dermatology and Venereology, University Hospital Centre Sestre Milosrdnice, Vinogradska cesta, 29, 10000 Zagreb, Croatia. Email: nikafilipovic07@gmail.com

\begin{abstract}
Dermoscopy is a diagnostic tool widely used in clinical practice for the detection of skin tumors, especially early stages of melanoma. Recent studies have shown that different dermoscopic features are associated with important prognostic parameters of melanoma, such as BRAF mutational status and sentinel lymph node status. More than half of all melanomas harbor a mutation in the BRAF oncogene. The current management of advanced-stage melanomas is greatly determined by the presence or absence of a mutation in this gene, as targeted therapy with $B R A F$ kinase inhibitors is one of the first therapeutic choices for these patients. Sentinel lymph node status is one of the most significant predictors of a melanoma patient's survival. Recent studies have shown that different dermoscopic patterns are also associated with sentinel lymph node status. This short article reviews studies that investigated correlations between dermoscopic features, BRAF mutation status and sentinel lymph node status.
\end{abstract}

\section{Introduction}

Melanoma is one of the most aggressive malignant skin tumors, with a rapidly increasing incidence over the course of the past 50 years worldwide, especially in fair-skinned Caucasian populations [1]. In 2018, approximately 300,000 new melanoma cases were registered globally [2].
Since the identification of $B R A F$ as an important oncogene in melanoma in 2002 [3], new therapeutic options have been developed and successfully implemented. The BRAF gene encodes a serine-threonine kinase that is a member of the MAPK [mitogen-activated protein kinase] signaling pathway. Approximately $50 \%-60 \%$ of melanomas harbor a $B R A F$ gene mutation, with the most common oncogenic alteration 
involving codon 600 [3]. A growing body of literature has demonstrated that different patterns of oncogene mutations correlate with different histological and clinical features of melanoma. In particular, there is a higher frequency of $B R A F$ mutations in melanomas of younger patients, melanomas located on the trunk, lesions of the superficial spreading histological subtype, and melanomas that develop on skin without chronic actinic damage [4-9].

Combined targeted therapy with small-molecule inhibitors of mutant BRAF and down-stream kinase MEK (MAPK inhibitors), as well as immunotherapy with inhibitors of PD-1 (programmed cell death receptor 1), represent today's first therapeutical choices for the majority of patients with metastatic melanoma [10]. Since this approach has significantly improved overall survival, assessment of $B R A F$ mutational status in tumor tissue, with standardized molecular methods, is crucial for treatment decisions.

Furthermore, it has been demonstrated that melanomas harboring BRAF mutations share certain morphological features detectable with noninvasive diagnostic tools such as dermoscopy [11]. In the past decades, dermoscopy has become a method widely used in clinical practice for detecting skin tumors, especially early stages of melanoma. Since $B R A F$-mutated melanomas show specific histomorphological features, specific dermoscopic features could be anticipated as well. However, only a few studies with heterogeneous results have been published on the relationship between dermoscopic patterns of melanoma and BRAF mutational status. As previously mentioned, since the current management of advanced-stage melanomas is greatly determined by the presence or absence of $B R A F$ mutations, identifying specific dermoscopic features associated with $B R A F$ mutational status before tumor excision could be of great importance in making further diagnostic and therapeutic decisions.

Sentinel lymph node (SLN) biopsy is a diagnostic procedure used to detect occult regional node melanoma metastases. According to international consensus and the latest American Joint Committee on Cancer classification from 2018 [12], SLN biopsy is generally indicated in melanomas with a thickness of $0.8 \mathrm{~mm}$ or more, and in lesions with ulceration. So far only sporadic studies regarding the correlation between dermoscopic patterns and SLN status have been conducted. Therefore, identifying specific dermoscopic features associated with SLN positivity could also be of great significance to clinicians in making a diagnostic-therapeutic algorithm for melanoma patients.

\section{Dermoscopic Features and $B R A F$ Mutational Status}

A study by Pozzobon et al [13] was one of the first to investigate the correlation between dermoscopic features and
MAPK mutational status. That study identified a significant association between dermoscopic regression, designated as “peppering”, and BRAF mutations $(\mathrm{OR}=1.68 ; 95 \% \mathrm{CI}$, 1.089-2.581, $\mathrm{P}=.015)$. In addition, after acral and facial melanomas [which may show different dermoscopic patterns $[14,15]$ were excluded from analysis, the presence of dermoscopic ulceration was also associated with $B R A F$ mutation status $(\mathrm{OR}=2.64 ; 95 \% \mathrm{CI}, 1.032-6.754 ; \mathrm{P}=.032)$.

Bombonato et al [16] reported that dermoscopic ulceration and irregular peripheral streaks are positive predictors of BRAF-mutated melanoma. It is well known that the dermoscopic presence of streaks is a sign of tumor growth and proliferation; in fact, streaks correspond to the presence of peripheral nests of tumor cells. However, they can also be seen in nevi (eg, Spitz/Reed nevi). On the other hand, the same study showed that the dermoscopic presence of dotted vessels was a negative predictor of BRAF-mutated melanomas. Only $10 \%$ of lesions with dotted vessels in that study were BRAF-mutated melanomas $(\mathrm{P}=.004)$. In contrast to the study by Pozzobon et al [13], regression in the form of dermoscopic peppering did not correlate with $B R A F$-mutated melanomas [16].

Fargnoli et al [17] did not identify any significant differences between dermoscopic features of BRAF-mutated and wild-type melanomas. These authors suggested that the limited number of dermoscopic images was the main limitation of their study.

Armengot-Carbó et al [18] showed a strong association between the presence of blue-white veil in dermoscopy and $B R A F$ mutations $(\mathrm{P}=.003)$. The blue-white veil corresponds to a large nest of intensely pigmented tumor cells located under a thickened epidermis [19-21]. Accordingly, histomorphological studies revealed that BRAF-mutated melanomas had a thicker epidermis and more pigmented cells with a greater tendency to form nests than wild-type melanomas $[22,23]$. Unfortunately, the study by Bombonato et al did not report data regarding this important dermoscopic pattern [16].

Furthermore, the study by Armengot-Carbó et al [18] did not show correlation between dermoscopic ulceration, dotted vessels and BRAF mutational status, as observed before [16]. This could be explained by the fact that, in the study by Bombonato et al [16], genetic testing was performed mainly when there was a clinical indication, that is, in predominantly thick melanomas. Consequently, there was also a higher mean Breslow thickness and higher ulceration frequency, and consequently a higher frequency of dermoscopic ulceration in their study, while in a study by Armengot-Carbó et al [18] there were no significant differences in Breslow thickness or histological ulceration. Although the presence of vascularization is in general a sign of tumor invasion and progression, dotted vessels are predominantly found in thin melanomas [24]. This 
could have affected their results due to the predominance of thicker melanomas in the BRAF-mutated group [16]. In addition, it should be noted that the number of melanomas with dermoscopic ulceration was higher than those with histological ulceration $[13,16,25]$, probably due to the higher sensitivity of dermoscopy, which can detect small peripheral ulcerations not found by histopathology due to sampling techniques [18].

Recently, Gouillon et al [26] reported an observational study of more than 100 melanomas that were compared dermoscopically and genetically. Pseudopods and radial projections were both observed more frequently in BRAF-mutated melanomas. Since these structures can be combined into "irregular peripheral streaks," these results are concordant with findings reported by Bombonato et al [16] and Armengot-Carbó et al [18]. Blue-gray peppering and white scar-like areas, dermoscopic features related to histological regression [27], were also more frequently found in $B R A F$-mutated melanomas than in wild-type lesions $(\mathrm{P}=.044)$. Concordant with the results of Armengot-Carbó et al [18], blue-white veil was more frequently present in the BRAF-mutated group $(\mathrm{P}=$.007). Additionally, Gouillon et al reported for the first time ever the parallel-ridge pattern as a negative predictor of $B R A F$ mutational status in acral lentiginous melanomas, as it was more frequently found in the wild-type melanoma group $(\mathrm{P}=.022)[26]$.

\section{Dermoscopic Features and Sentinel Lymph Node Positivity}

As metastases from melanoma most frequently develop in lymph nodes, SLN biopsy has emerged as a key diagnostic tool for determining whether cancer has spread to the regional lymph nodes. This minimally invasive procedure has successfully replaced elective lymph node dissection in the management of melanoma patients [28,29]. According to several studies, histological features of the primary lesion and SLN biopsy are the most significant predictors of a melanoma patient's survival [30,31]. González-Álvarez et al [32] investigated the association between dermoscopic structures and SLN status, and found that the presence of an atypical pigmented network was associated with a negative SLN. A dermoscopic pigmented network represents pigmented rete ridges histologically, so thicker melanomas lose these rete ridges due to tumor progression and invasion of the dermis. Consequently, it is evident that in thick melanomas, where SLN biopsy is done, a dermoscopic atypical pigmented network is often not found. On the other hand, the presence of dermoscopic ulceration and blotches [area of homogeneous dark pigmentation] correlated with a positive SLN. The presence of a blue-white veil, atypical vessels and regression structures was not significantly correlated to SLN status.
Pagnanelli et al [33] failed to identify any predictive dermoscopic criteria for SLN positivity in melanomas thicker than $1 \mathrm{~mm}$. This outcome could be explained by the fact that only $23 \%$ of patients studied had melanomas thicker than 1 $\mathrm{mm}$ requiring SLN biopsy.

\section{Conclusions}

Even though dermoscopy cannot replace molecular methods and histopathology in determining BRAF mutational status and SLN status, it could be a useful additional diagnostic tool in predicting these melanoma features. Different dermoscopic patterns (eg, blue-white veil, ulceration, peppering) have been identified as significant predictors of $B R A F$ mutational status and SLN status, and therefore could be of great significance in making diagnostic-therapeutic algorithms for melanoma patients. However, further studies are needed to investigate these findings and identify other dermoscopic criteria associated with BRAF mutations and SLN positivity.

\section{References}

1. National Cancer Institute. (2020, April 15). Surveillance, Epidemiology, and End Results (SEER). Program Cancer Statistics Review, 1975-2017. Accessed August 20, 2020. https://seer. cancer.gov/csr/1975-2017

2. Bray F, Ferlay J, Soerjomataram I, Siegel RL, Torre LA, Jemal A. Global cancer statistics 2018: GLOBOCAN estimates of incidence and mortality worldwide for 36 cancers in 185 countries. CA Cancer J Clin. 2018;68(6):394-424. DOI: 10.3322/caac.21492. PMID: 30207593.

3. Davies H, Bignell GR, Cox C, et al. Mutations of the BRAF gene in human cancer. Nature. 2002;417(6892):949-54. DOI: 10.1038/nature00766.

4. Lee JH, Choi JW, Kim YS. Frequencies of BRAF and NRAS mutations are different in histological types and sites of origin of cutaneous melanoma: a meta-analysis. Br J Dermatol. 2011;164(4):776-784. DOI: 10.1111/j.1365-2133.2010.10185.x. PMID: 21166657.

5. Kim SY, Kim SN, Hahn HJ, Lee YW, Choe YB, Ahn KJ. Metaanalysis of BRAF mutations and clinicopathologic characteristics in primary melanoma. J Am Acad Dermatol. 2015;72(6):10361046.e2. DOI: 10.1016/j.jaad.2015.02.1113. PMID: 25819940.

6. Liu W, Kelly JW, Trivett M, et al. Distinct clinical and pathological features are associated with the BRAF ${ }^{\mathrm{T} 1799 \mathrm{~A}(\mathrm{~V} 600 \mathrm{E})}$ mutation in primary melanoma. J Invest Dermatol. 2007;127(4):900-905. DOI: 10.1038/sj.jid.5700632. PMID: 17159915.

7. Thomas NE, Edmiston SN, Alexander A, et al. Association between NRAS and BRAF mutational status and melanoma-specific survival among patients with higher-risk primary melanoma. JAMA Oncol. 2015;1(3):359-368. DOI: 10.1001/jamaoncol.2015.0493. PMID: 26146664.

8. García-Casado Z, Traves V, Bañuls J, et al. BRAF, NRAS and MC1R status in a prospective series of primary cutaneous melanoma. Br J Dermatol. 2015;172(4) 1128-1131. DOI: 10.1111/ bjd.13521. PMID: 25385688. 
9. Bauer J, Büttner P, Murali R, et al. BRAF mutations in cutaneous melanoma are independently associated with age, anatomic site of the primary tumor, and the degree of solar elastosis at the primary tumor site. Pigment Cell Melanoma Res. 2011;24(2):345-351. DOI: 10.1111/j.1755-148X.2011.00837.x. PMID: 21324100.

10. Coit DG, Thompson JA, Algazi A, et al. NCCN Guidelines insights: Melanoma, version 3.2016. J Natl Compr Canc Netw. 2016;14(8):945-958. DOI: 10.6004/jnccn.2016.0101. PMID: 27496110.

11. Gandolfi G, Longo C, Moscarella E, et al. The extent of whole-genome copy number alterations predicts aggressive features in primary melanomas. Pigment Cell Melanoma Res. 2016;29(2):163175. DOI: 10.1111/pcmr.12436. PMID: 26575206.

12. Gershenwald JE, Colyer RA. Melanoma Staging: American Joint Committee on Cancer (AJCC) 8th Edition and Beyond. Ann Surg Oncol. 2018;25(8):2105-2110. DOI: 10.1245/s10434-0186513-7.

13. Pozzobon FC, Puig-Butillé JA, González-Alvarez T, et al. Dermoscopic criteria associated with BRAF and NRAS mutation status in primary cutaneous melanoma. Br J Dermatol. 2014;171(4):754759. DOI: 10.1111/bjd.13069. PMID: 24749938.

14. Phan A, Dalle S, Touzet S, Ronger-Savlé S, Balme B, Thomas L. Dermoscopic features of acral lentiginous melanoma in a large series of 110 cases in a white population. Br J Dermatol. 2010;162(4):765-771. DOI: 10.1111/j.1365-2133.2009.09594.x. PMID: 19922528.

15. Pralong P, Bathelier E, Dalle S, Poulalhon N, Debarbieux S, Thomas L. Dermoscopy of lentigo maligna melanoma: report of 125 cases. Br J Dermatol. 2012;167(2):280-287. DOI: 10.1111/j.1365-2133.2012.10932.x. PMID: 22404578.

16. Bombonato C, Ribero S, Pozzobon FC, et al. Association between dermoscopic and reflectance confocal microscopy features of cutaneous melanoma with BRAF mutational status. J Eur Acad Dermatol Venereol. 2017;31(4):643-649. DOI: 10.1111/ jdv.14028. PMID: 27790766.

17. Fargnoli MC, Sera F, Suppa M, et al. Dermoscopic features of cutaneous melanoma are associated with clinical characteristics of patients and tumours and with MC1R genotype. J Eur Acad Dermatol Venereol. 2014;28(12):1768-1775. DOI: 10.1111/ jdv.12411. PMID: 24588892.

18. Armengot-Carbó M, Nagore E, García-Casado Z, Botella-Estrada R. The association between dermoscopic features and BRAF mutational status in cutaneous melanoma: Significance of the blue-white veil. J Am Acad Dermatol. 2018;78(5):920-926.e4. DOI: 10.1016/j.jaad.2017.12.064, PMID: 29307636.

19. Malvehy J, Puig S. Principles of Dermoscopy. Barcelona: Cege Editors, 2002.

20. Argenziano G, Soyer HP, Chimenti S, et al Dermoscopy of pigmented skin lesions: results of a consensus meeting via the internet. J Am Acad Dermatol. 2003;48(5):679-693. DOI: 10.1067/ mjd.2003.281. PMID: 12734496.

21. Neila J, Soyer HP. Key points in dermoscopy for diagnosis of melanomas, including difficult to diagnose melanomas, on the trunk and extremities. J Dermatol. 2011;38(1):3-9. DOI: 10.1111/j.1346-8138.2010.01131.x. PMID: 21175749.

22. Viros A, Fridlyand J, Bauer J, et al. Improving melanoma classification by integrating genetic and morphologic features. PLOS Med. 2008;5(6):e120. DOI: 10.1371/journal.pmed.0050120. PMID: 18532874.

23. Broekaert SMC, Roy R, Okamoto I, et al. Genetic and morphologic features for melanoma classification. Pigment Cell Melanoma Res. 2010;23(6):763-770. DOI: 10.1111/j.1755148X.2010.00778.x. PMID: 20874733.

24. Zalaudek I, Kreusch J, Giacomel J, Ferrara G, Catrical C, Argenziano G. How to diagnose nonpigmented skin tumors: a review of vascular structures seen with dermoscopy: part I. Melanocytic skin tumors. J Am Acad Dermatol. 2010. p. 361-74. DOI: 10.1016/j.jaad.2009.11.698. PMID: 20708469.

25. Deinlein T, Arzberger E, Zalaudek I, et al. Dermoscopic characteristics of melanoma according to the criteria "ulceration" and, "mitotic rate" of the AJCC 2009 staging system for melanoma. PLoS ONE. 2017;12(4):e0174871. DOI: 10.1371/journal. pone.0174871. PMID: 28399177.

26. Gouillon L, Perier-Muzet M, Amini-Adle M, et al. Dermoscopic features in BRAF and NRAS primary cutaneous melanoma: association with peppering and blue-white veil. J Eur Acad Dermatol Venereol. 2020;34(2):357-e59 DOI: 10.1111/jdv.15906. PMID: 31442328.

27. Zalaudek I, Argenziano G, Ferrara G, et al. Clinically equivocal melanocytic skin lesions with features of regression: a dermoscopic-pathological study. Br J Dermatol. 2004;150(1):64-71. DOI: 10.1111/j.1365-2133.2004.05657.x. PMID: 14746618.

28. Gonzalez A. Sentinel lymph node biopsy: past and present implications for the management of cutaneous melanoma with nodal metastasis. Am J Clin Dermatol. 2018;19(Suppl 1):24-30 DOI: 10.1007/s40257-018-0379-0. PMID: 30374897.

29. Morton DL, Thompson JF, Cochran AJ, et al. Final trial report of sentinel-node biopsy versus nodal observation in melanoma. N Engl J Med. 2014;370(7):599-609. DOI: 10.1056/NEJMoa1310460. PMID: 24521106.

30. Thomson DR, Rughani MG, Kuo R, Cassell OCS. Sentinel node biopsy status is strongly predictive of survival in cutaneous melanoma: Extended follow-up of Oxford patients from 1998 to 2014. J Plast Reconstr Aesthet Surg. 2017;70(10):1397-1403. DOI: 10.1016/j.bjps.2017.05.025. PMID: 28625757.

31. Tejera-Vaquerizo A, Ribero S, Puig S, et al. Survival analysis and sentinel lymph node status in thin cutaneous melanoma: a multicenter observational study. Cancer Med. 2019;8(9):4235-4244. DOI: 10.1002/cam4.2358. PMID: 31215168.

32. González-Álvarez T, Carrera C, Bennassar A, et al. Dermoscopy structures as predictors of sentinel lymph node positivity in cutaneous melanoma. Br J Dermatol. 2015;172(5):1269-1277. DOI: 10.1111/bjd.13552. PMID: 25418318.

33. Pagnanelli G, Bono R, Pizzichetta MA, et al. Clinical and dermoscopic criteria related to melanoma sentinel lymph node positivity. Anticancer Res. 2007;27(4C):2939-2944. PMID: 17695474. 